\title{
LIMITES E POSSIBILIDADES DA INTERSECC̣ÃO ENTRE DIREITOS HUMANOS E EMPRESAS
}

http://dx.doi.org/10.1590/2317-6172201813

Este número da Revista Direito GV é composto por duas partes. A primeira parte do volume traz um dossiê, do qual constam os artigos da chamada temática "Empresas e Direitos Humanos", idealizada e editada em parceria com Ângela PiresTerto, assessora de direitos humanos da ONU Brasil, Silvia Generali da Costa, professora associada da Universidade Federal do Rio Grande do Sul (UFRGS), e Flávia Scabin, professora e pesquisadora da Escola de Direito de São Paulo da Fundação Getulio Vargas (FGV DIREITO SP). A segunda parte traz artigos inéditos sobre temas variados, recebidos pelo processo de submissão contínuo da revista.

Neste editorial, falaremos sobre o tema da chamada temática, os manuscritos recebidos e o processo de avaliação. Ao fim, apresentaremos brevemente os artigos publicados.

A relação entre direitos humanos e empresas passou a ganhar destaque na agenda internacional a partir da década de 1990, sobretudo diante das novas realidades trazidas pelo processo de globalização corporativa. ${ }^{1}$ A abertura dos mercados, atrelada à expansão das empresas e de suas cadeias para além das fronteiras de seu país de origem e ao aumento de sua capacidade econômica ${ }^{2}$ e, com isso, da sua capacidade de influenciar o contexto de suas operações, fez com que a discussão acerca do compromisso com os Direitos Humanos, tradicionalmente focada nos Estados, passasse também a incorporar as empresas (FUNDAÇÃO GETULIOVARGAS, 2017).

Isso se deu em decorrência de evidências, cada vez mais frequentes, da presença do trabalho infantil e do trabalho forçado nas cadeias de fornecimento das grandes corporações transnacionais, diante do acontecimento de uma série de desastres socioambientais associados aos negócios e ainda do envolvimento de empresas com grupos paramilitares de países em conflito. ${ }^{3}$

1 O conceito de globalização corporativa é empregado por Ruggie (2013, p. 17) para designar o processo de reestruturação produtiva pelo qual as empresas transnacionais conseguiram estabelecer redes corporativas que ultrapassaram as economias nacionais e construíram núcleos de atividades econômicas sujeitos a uma única visão global estratégica.

2 Segundo dados sistematizados pelo Global Justice Now (2016), a partir da comparação direta entre as receitas anuais das empresas e as receitas anuais dos países, dentre as 100 maiores economias do mundo, 69 eram empresas no ano de 2015. Esses dados foram apresentados pela Fortune Global 500.

3 John Ruggie elenca o caso da marca Chiquita Brands como um exemplo de envolvimento indireto das companhias em violações de direitos humanos. A empresa em questão foi considerada cúmplice da violência paraestatal quando acusada de recrutar forças paramilitares de direita na Colômbia para proteger as suas instalações e quando esses grupos foram acusados de matar guerrilheiros e sindicalistas (RUGGIE, 2013, p. 155). 
No âmbito dos Estados nacionais, foi o crescimento econômico, atrelado à realização de projetos de infraestrutura, que colocou as empresas no polo ativo de grandes violações de direitos humanos, sobretudo nos países em desenvolvimento. Deslocamentos forçados de comunidades tradicionais, ${ }^{4}$ contaminação, aumento de violência e da exploração sexual de crianças e adolescentes são alguns dos exemplos das dezesseis violações a direitos recorrentemente associadas à construção de barragens, segundo apurou o Conselho de Defesa dos Direitos da Pessoa Humana (2007), com base na análise de denúncias realizadas contra sete empreendimentos hidrelétricos.

Diante dessa realidade, indivíduos e comunidades afetados de forma negativa pela globalização corporativa começaram a fazer uso da linguagem dos direitos humanos para expressar suas reivindicações e buscar ressarcimento dos custos humanos implicados nesse processo.

Nesse sentido, defensores dos direitos humanos e empresas transnacionais entraram em choque a fim de responder como as regras para a defesa dos direitos humanos poderiam ser inseridas na prática corporativa e dos governos. No âmbito internacional, a Subcomissão da ONU de Promoção e Proteção dos Direitos Humanos já vinha trabalhando desde o começo dos anos 1990 na elaboração de um documento de Normas de Responsabilidades de Corporações Transnacionais e Outras Empresas em Relação aos Direitos Humanos. ${ }^{\mathbf{5}}$ Em 2003, o texto foi apresentado perante a então Comissão de Direitos Humanos (atual Conselho de Direitos Humanos), onde enfrentou forte resistência por parte das empresas e não teve seguimento.

Naquele momento, as empresas descreveram a tentativa como "privatização dos direitos humanos", porque transferia às empresas obrigações que consideravam ser de responsabilidade exclusiva do Estado (RUGGIE, 2013, p. 19). No entanto, ao longo dos anos as empresas passaram por um processo de entendimento acerca dos efeitos econômicos e dos riscos de desrespeitarem os direitos humanos, mesmo quando estes sejam entendidos apenas como normas sociais. O caso da

4 Recentemente, o caso mais emblemático no Brasil tem sido a expulsão de famílias de ribeirinhos para a construção da usina hidrelétrica de Belo Monte, no Xingu. Conforme Scabin et al. (2017, p. 125), "a expulsão de um grupo social de um território tradicionalmente ocupado intensifica a desigualdade, o conflito social, a segregação e dispersão das famílias e põe fim à uma complexa rede de parentescos e vizinhança que constituíam mecanismos eficientes de ajuda mútua e proteção territorial".

$5 \quad$ No entanto, já nas décadas de 1960 e 1970, as atividades das empresas transnacionais começaram a ser objeto de debate, especialmente quanto a seus impactos na questão do trabalho e das políticas sociais. Tais preocupações serviram para a criação da Declaração Tripartite de Princípios sobre Empresas Multinacionais e Política Social, por parte da OIT, em 1977. Os princípios preconizados nesse instrumento internacional oferecem orientações em matéria de emprego, formação, condições de trabalho e de vida e de relações de trabalho para empresas transnacionais, governos, empregadores e trabalhadores (ORGANIZAÇÃO INTERNACIONAL DO TRABALHO, 2002). 
Shell, no território de Ogoni, na Nigéria, é um exemplo de como uma empresa transnacional pode perder sua licença social para operação em certo local, por meio da mobilização popular, antes mesmo de sua licença legal ser anulada formalmente pelo governo (RUGGIE, 2013, p. 148).

A retomada da discussão sobre empresas e direitos humanos no âmbito da ONU deu-se com a nomeação de John Ruggie como Representante Especial do Secretário-Geral sobre Empresas e Direitos Humanos, o que resultou, após anos de estudos e visitas aos diferentes continentes, na publicação do relatório intitulado Proteger, respeitar e remediar: um marco sobre empresas e Direitos Humanos, em 2008, e na adoção dos Princípios Orientadores sobre Empresas e Direitos Humanos (POs) (CONECTAS, 2012), pelo Conselho de Direitos Humanos das Nações Unidas, em 2011.

A principal contribuição dos POs foi estabelecer que os direitos humanos, já definidos nos principais tratados e convenções internacionais, também devem orientar os negócios. Isso implica por parte dos Estados que se comprometeram com os POs, a assunção das novas obrigações de prevenir, investigar, punir e reparar violações a direitos cometidas por empresas; e o estabelecimento de novas obrigações para as empresas, de não violar os direitos humanos e enfrentar os impactos negativos sobre os direitos humanos sobre quais tenham alguma responsabilidade, dentro de seus estabelecimentos, por meio de suas operações em cadeia e no seu entorno.

Por ter se comprometido com os POs, o Brasil foi o primeiro país da América Latina a receber visita oficial do Grupo de Trabalho das Nações Unidas sobre Direitos Humanos, Corporações Transnacionais e outras Empresas (GT ONU Empresas e Direitos Humanos), cuja missão era identificar os esforços realizados pelo país e as lacunas e obstáculos para a proteção dos direitos humanos no âmbito dos negócios. Uma série de desafios foi apontada pelo relatório do GT, dentre eles a baixa disseminação das novas expectativas estabelecidas pelos POs, sobretudo entre as empresas (UNITED NATIONS, 2016).

Diante desse contexto é que, em 2017, a Revista Direito GV, em parceria com o Centro de Direitos Humanos e Empresas da FGV, a Organização das Nações Unidas no Brasil (ONU Brasil) e a Universidade Federal do Rio Grande do Sul (UFRGS), realizou uma chamada especial de artigos com a temática "Empresas e Direitos Humanos". 6

A temática tem sido objeto de pesquisa na FGV DIREITO SP desde 2013, quando foi criado o Centro de Direitos Humanos e Empresas, coordenado pela professora e pesquisadora Flávia Scabin. Nos últimos anos, o Centro se dedicou à elaboração de diversos diagnósticos sobre temas como: os

6 A seleção dos artigos não implica endosso do seu conteúdo por parte das instituições referidas. 
impactos de grandes empreendimentos de infraestrutura nos direitos de crianças e adolescentes; as violações aos direitos fundamentais dos trabalhadores em cadeias de fornecimento na indústria têxtil; e o deslocamento forçado de pessoas em grandes obras, entre outros. As pesquisas já resultaram na criação de parâmetros para políticas públicas governamentais e instrumentos para que as empresas possam avaliar seus riscos e prevenir violações aos direitos humanos em suas atividades.

É inegável a capacidade de influência das empresas tanto, por um lado, para efetivar investimentos e potencialmente gerar desenvolvimento econômico local, como, por outro lado, de provocar transformações profundas no meio ambiente e no campo social onde os empreendimentos se realizam. Com isso, é muito relevante discutir o papel das empresas no desenvolvimento dos países em que são sediadas e também em que operam. Nesse contexto, buscamos com a chamada fomentar a produção acadêmica que trabalha com as diversas problemáticas da relação entre direitos humanos e empresas.

A Revista recebeu, ao todo, 64 artigos para avaliação dentro da temática da chamada especial. O primeiro ponto a se notar foi que, embora a chamada tenha elencado doze eixos temáticos como referência, ${ }^{7}$ não se verificou grande variedade nesse sentido, isto é, os artigos apresentados focaram apenas alguns temas específicos, conforme o gráfico a seguir:

\section{TEMAS DOS ARTIGOS RECEBIDOS}

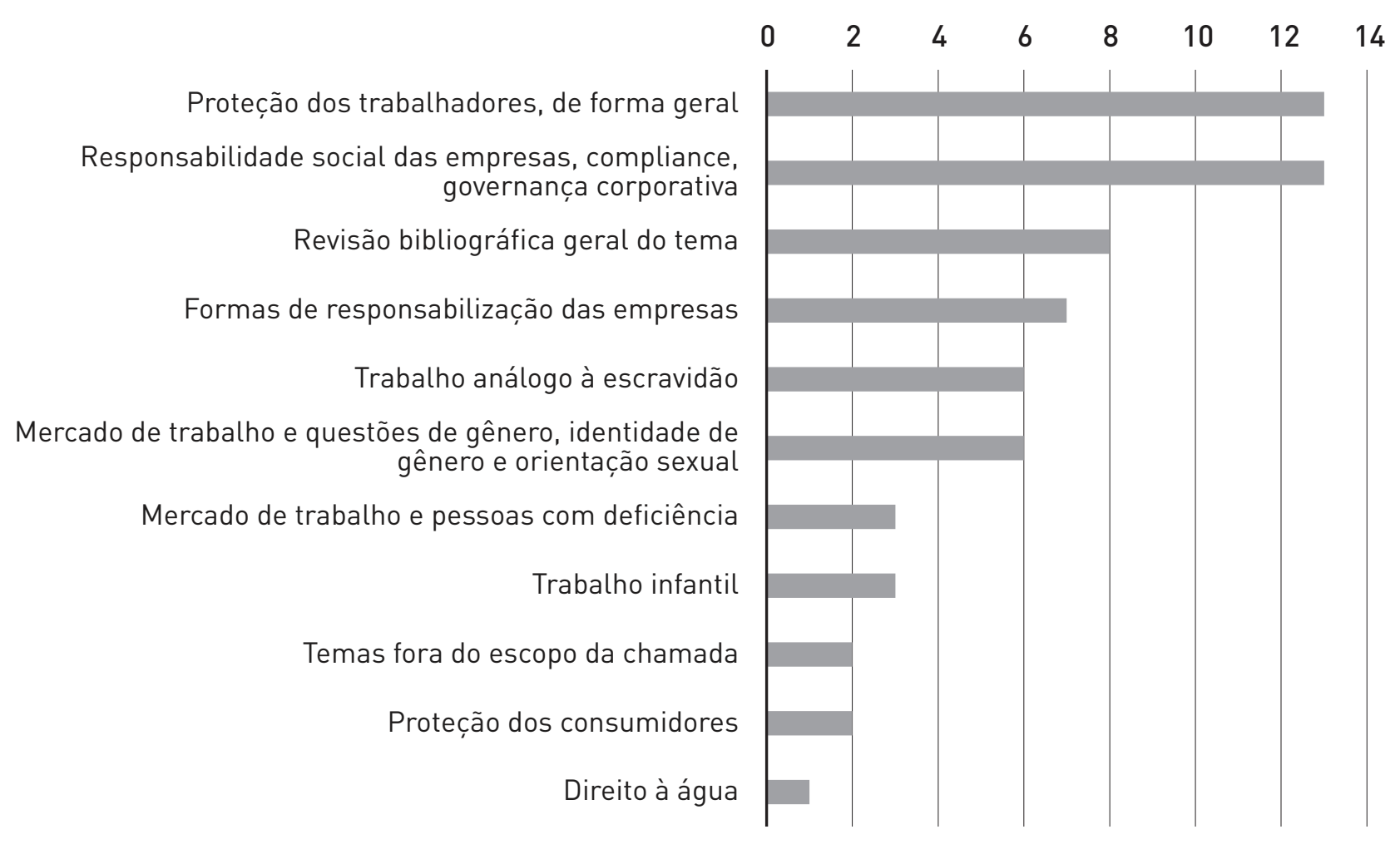

7 (i) A aplicação dos princípios orientadores sobre empresas e direitos humanos no Brasil; (ii) a responsabilidade do Estado no tema "empresas e direitos humanos"; (iii) instrumentos empresariais para o controle de impactos em direitos humanos; (iv) acesso a mecanismos de reparação; (v) discriminação no ambiente de trabalho; (vi) 
O que pudemos notar é que grande parte dos artigos que recebemos abordou as relações de trabalho e os riscos e violações a direitos nesse âmbito, ao passo que um número reduzido de artigos trouxe à discussão os diferentes impactos potencialmente exercidos pelas atividades empresariais, que vão além das relações trabalhistas e podem envolver a relação da empresa com o meio ambiente e as comunidades do entorno.

Com isso, destacamos a necessidade de mais pesquisas que possam tratar das responsabilidades das empresas ao longo de suas cadeias produtivas, dos instrumentos que podem ser implementados para prevenir e controlar os riscos e violações a direitos no entorno de operações, dos desafios e oportunidades para que as políticas possam garantir o acesso à justiça para vítimas de violações. Além disso, mostra-se essencial analisar as violações de direitos humanos de forma interseccional, isto é, com base nos diferentes marcadores identitários das pessoas afetadas, tais como raça, cor, etnia, gênero, idade, orientação sexual e identidade de gênero. Outras questões pertinentes a esse âmbito se relacionam, por exemplo, com as responsabilidades das empresas para a garantia de um ambiente de trabalho diverso e inclusivo e com o perfil das pessoas que são afetadas pelas ações empresariais e que sofrem mais com a precarização das relações de trabalho.

Do ponto de vista metodológico, é preciso ressaltar que a maior parte dos textos recebidos tinha a revisão bibliográfica como metodologia principal ou única. O levantamento bibliográfico do que já foi produzido na área é etapa essencial da pesquisa e o início do artigo deve apontar os avanços já alcançados pela literatura da área. Entretanto, procuramos sempre privilegiar as pesquisas que dão um passo além, isto é, elaboram novas teorias, ideias, concepções e soluções sobre os temas e as questões, especialmente aquelas que empregam métodos empíricos.

Assim, os textos que fizeram simples revisões bibliográficas ou acabaram tratando das questões de forma muito superficial, apenas com indicação das questões enfrentadas na área, não prosseguiram na avaliação. Como exposto na política editorial da Revista, priorizamos textos que contribuam com a inovação, metodológica e teórica, e principalmente que examinem o papel do direito, das instituições jurídicas e dos sistemas jurídicos nacionais e internacionais nos processos de desenvolvimento social e econômico, algo que a mera revisão de literatura dificilmente traz.

Por outro lado, destacamos o recebimento de textos de qualidade e que abordaram temáticas importantes em profundidade. Após o processo de avaliação da Revista, publicamos neste volume quatro artigos que tratam de direitos humanos e empresas sob diferentes perspectivas.

segurança dos/das trabalhadores/as; (vii) terceirização; (viii) trabalho análogo ao trabalho escravo; (ix) trabalho infantil; (x) liderança e responsabilidade; (xi) grandes empreendimentos e impactos no entorno; (xii) temas livres sobre empresas e direitos humanos. 
A pesquisa de Cecília Barreto e Victor Vasconcellos, intitulada "Transexuais: transpondo barreiras no mercado de trabalho em São Paulo?" explorou as dificuldades de acesso ao mercado de trabalho por parte de pessoas transexuais, transgênero e travestis. A dupla realizou entrevistas com importantes atores e atrizes sociais para traçar um perfil das dificuldades encontradas pela população trans e possíveis soluções para garantir o pleno acesso ao direito ao trabalho. ${ }^{8}$

Ainda no âmbito de populações vulnerabilizadas, a pesquisa de Regiane Oliveira apresentou as vivências e os relatos de trabalhadores resgatados de situação análoga à escravidão, no caso da Fazenda Brasil Verde, que teve decisão da Corte Interamericana de Direitos Humanos. Seu texto intitulado “Seeking victims' perspective on remedy: the case of Brazil Verde Farm's workers" aborda as vontades e necessidades dos trabalhadores resgatados e os possíveis remédios legais para retirá-los de sua situação vulnerável.

O artigo de Maiquel Wermuth e Joice Nielsson trata também do caso da Fazenda Brasil Verde, porém sob outra perspectiva. O texto intitulado "A 'empresa-campo' e a produção da 'vida nua': direitos humanos e o trabalho escravo contemporâneo sob a perspectiva biopolítica" analisa se as empresas que mantêm trabalhadores em situação de escravidão podem ser compreendidas no conceito de campo do filósofo Giorgio Agamben, que não vê o direito como um contraponto civilizatório, mas sim como parte do processo de produção da vida nua, articulado a relações de exploração e dominação.

Por fim, o texto escrito em coautoria por Gabriel Galil, Manoela Roland, Daniel de Aragão, Paola Angelucci, Arindo Duque Neto e Rafael Neto traz críticas importantes sobre a responsabilização das empresas. $\mathrm{O}$ artigo intitulado "Desafios e perspectivas para a construção de um instrumento jurídico vinculante em direitos humanos e empresas" traz os referenciais teóricos da "arquitetura da impunidade", defendendo a insuficiência do atual modelo de responsabilização das empresas e sugerindo alternativas em busca de maior eficácia.

Esperamos que a publicação desses artigos possa contribuir com as discussões e as pesquisas sobre a temática, em seus diversos aspectos. Lembramos que a Revista Direito GV continua aberta a tais debates por meio de nosso processo contínuo de submissão de artigos e desejamos uma boa leitura!

8 Nesse contexto, podemos destacar que recentemente o Alto Comissariado das Nações Unidas para os Direitos Humanos interpretou os Princípios Orientadores sob a perspectiva da garantia dos direitos de pessoas LGBTI (lésbicas, gays, bissexuais, travestis, transexuais, pessoas trans e intersexo) e publicou os Padrões de conduta para empresas: enfrentando a discriminação contra pessoas LGBTI (UNITED NATIONS, 2017). Este pode ser um convite à realização de pesquisas dedicadas a essa temática, que ainda conta com pouca produção acadêmica, sobretudo no campo de dados quantitativos. 


\section{REFERÊNCIAS}

CONECTAS. Empresas e Direitos Humanos: parâmetros da ONU para proteger, respeitar e reparar. Relatório final de John Ruggie - Representante Especial do Secretário-Geral. São Paulo: Conectas, 2012. Disponível em: <http://www.conectas.org/publicacoes/download/empresas-e-direitos-humanos-parametros-daonu>.Acesso em: 10 jul. 2018.

CONSELHO DE DEFESA DOS DIREITOS DA PESSOA HUMANA. Comissão Especial "Atingidos por Barragens". Resoluções 26/06, 31/06, 01/07, 02/07, 05/07. Relatório Síntese. Brasília, 2007. Disponível em: <http://www.mpf.mp.br/atuacao-tematica/ccr6/dados-da-atuacao/encontrosnacionais-e-regionais/xi-encontro-nacional/xi-encontro/legislacao/relatorio-sintese-cddph>. Acesso em: 2 maio 2018.

FUNDAÇÃO GETULIO VARGAS. Centro de Direitos Humanos e Empresas. Implementando os princípios orientadores sobre empresas e direitos humanos: o dever do Estado de proteger e a obrigação das empresas de respeitar os direitos humanos. Brasília, 2017. Disponível em: <http://www.mdh.gov.br/sdh/noticias/ 2017/novembro/cartilha-empresas-e-direitos-humanos-1/view >. Acesso em: 10 jul. 2018.

GLOBAL JUSTICE NOW. Corporations running the world used to be science fiction - Now it's a reality. 12 set. 2016. Disponível em: <http://www.globaljustice.org.uk/blog/2016/sep/12/corporationsrunning-world-used-be-science-fiction-now-its-reality>. Acesso em: 2 maio 2018.

ORGANIZAÇÃO INTERNACIONAL DO TRABALHO (OIT). Declaração tripartite de princípios sobre empresas multinacionais e política social. Brasília: Organização Internacional do Trabalho, 2002. Disponível em: <http://www.ilo.org/brasilia/publicacoes/WCMS_227046/lang_pt/index.htm>. Acesso em: 10 jul 2018.

RUGGIE, John Gerard. Quando negócios não são apenas negócios: as corporações multinacionais e os Direitos Humanos. São Paulo: Planeta Sustentável, 2013.

SCABIN, Flávia et al. A violação de direitos dos ribeirinhos no contexto de Belo Monte e os processos de assistência jurídica da DPU, em Altamira. In: MAGALHÃES, Sônia Barbosa; CUNHA, Manuela Carneiro da (Orgs). A expulsão dos ribeirinhos em Belo Monte. São Paulo: SBPC, 2017.

UNITED NATIONS. Human Rights, Office of the High Comissioner. Padrões de conduta para empresas: enfrentando a discriminação contra pessoas LGBTI. Nova Iorque, 2017. Disponível em: <https:// www.unfe.org/wp-content/uploads/2018/04/Padroes-de-conduta-para-empresas.pdf $>$. Acesso em: 2 maio 2018. 
. Report of theWorking Group on the issue of human rights and transnational corporations and other business enterprises on its mission to Brazil. Genebra, 2016. Disponível em: <http://ap.ohchr.org/documents/ dpage_e.aspx?si=A/HRC/32/45/Add.1>.Acesso em: 2 maio 2018.

\section{Catarina Helena Cortada Barbieri}

https://orcid.org/0000-0002-0332-7063

Fundação Getulio Vargas São Paulo - SP - Brasil

EDITORA-CHEFE dA REVISTA DiREITO GV.

Professora da Escola de Direito de São Paulo da Fundação Getulio Vargas (FGV Direito SP). Mestre e Doutora em Direito pela Universidade de São Paulo (USP).

catarina.barbieriafgv.br

Flávia Scabin

https://orcid.org/0000-0001-7153-9052

Fundação Getulio Vargas São Paulo - SP - Brasil

Professora e Pesquisadora da Escola de Direito de São Paulo da Fundação Getulio Vargas (FGV Direito SP), onde COORDENA O CENTRO DE PESQUISA APLICADA EM DIREITOS Humanos e Empresas. Graduada em Direito Pela Pontifícia Universidade Católica de São Paulo (PUC-SP). Mestre em

Ciência Política pela Faculdade de Filosofia, Letras e

Ciências humanas da Universidade de São Paulo (USP), TENDO REALIZADO CURSO DE ESPECIALIZAC̣ÃO DO CENTRO

UNIVERSITÁRIO EUROPEU.

flavia.scabinafgv.br

\section{Juliana Silva Pasqua}

https://orcid.org/0000-0002-0107-6344

Fundação Getulio Vargas São Paulo - SP - Brasil

Assistente editorial da ReVISTA DiReito GV. Pesquisadora da área de Publicações na Escola de Direito de São Paulo da Fundação Getulio VARgas (FGV DiREITO SP). LL.M. EM DiREITOS FUNDAMENTAIS PELA LUDWIG-MAXIMILIANS-UNIVERSITÄT DE Munique (LMU) E GRADUADA EM DIREITO PELA UNIVERSIDADE DE SÃo PAULO (USP).

juliana.pasqualafgv.br 


\section{Leila Giovana Izidoro}

https://orcid.org/0000-0002-5119-076X

Universidade de São Paulo São Paulo - SP - Brasil

Assistente editorial da Revista Direito GV. Pesquisadora da área de Publicações na Escola de Direito de São Paulo da Fundação Getulio Vargas (FGV Direito SP). Mestranda no Programa de Pós-Graduação em Direitos humanos da Universidade de São PaUlo (USP).

leila.izidorolafgv.br 